\title{
Towards a Tailored Engineering Design Process for Individualized Micro-Mechatronic Systems with a Novel Case-Based Methodology
}

\author{
Faruk Civelek ${ }^{1,2, *}$, Karl-Peter Fritz ${ }^{1}$ and André Zimmermann ${ }^{1,2}$ (D) \\ 1 Hahn-Schickard, Allmandring 9b, 70569 Stuttgart, Germany; Karl-Peter.Fritz@Hahn-Schickard.de (K.-P.F.); \\ Andre.Zimmermann@Hahn-Schickard.de (A.Z.) \\ 2 Institute for Micro Integration (IFM), University of Stuttgart, Allmandring 9b, 70569 Stuttgart, Germany \\ * Correspondence: Faruk.Civelek@ifm.uni-stuttgart.de; Tel.: +49-711-685-60782
}

Citation: Civelek, F.; Fritz, K.-P.; Zimmermann, A. Towards a Tailored Engineering Design Process for Individualized Micro-Mechatronic Systems with a Novel Case-Based Methodology. Appl. Sci. 2021, 11, 7909. https://doi.org/10.3390/ app11177909

Academic Editor: Emanuele Carpanzano

Received: 6 July 2021

Accepted: 24 August 2021

Published: 27 August 2021

Publisher's Note: MDPI stays neutral with regard to jurisdictional claims in published maps and institutional affiliations.

Copyright: (c) 2021 by the authors. Licensee MDPI, Basel, Switzerland. This article is an open access article distributed under the terms and conditions of the Creative Commons Attribution (CC BY) license (https:// creativecommons.org/licenses/by/ $4.0 /)$.

\begin{abstract}
The development and manufacturing of high-precision micro-mechatronic systems (MMS) is a challenging task, and the high demand for individualized products complicates the engineering design process (EDP) in particular. The established EDP for MMS is not designed for individualized products. This article gives an overview of the challenges (critical factors) in product development and manufacturing of individualized MMS (iMMS), a novel definition of iMMS, and describes a new qualitative methodology in order to tailor an EDP based on use cases, so-called "Tailored EDP-Methodology" (TEDP-Methodology). This TEDP-Methodology allows creating use-case-based product groups through the abstraction of the use cases and evaluating the requirements, which is essential to tailor or develop a new EDP. For the development of this new approach, a literature review and qualitative content analysis are prefaced. The TEDP-Methodology is critically examined and validated with a real case study for the development and manufacturing of an iMMS. This study shows critical points within the EDP. It shows fields of action for innovative tools to support the development process of iMMS and requirements for different product groups within iMMS. This article has both theoretical and practical implications.
\end{abstract}

Keywords: engineering design process; micro-mechatronic systems; customization; individualization; digital manufacturing technologies; use cases

\section{Introduction}

This section shall highlight the relevance of MMS and/or iMMS and explain its suitable technologies and the necessity for new methodological approaches for iMMS (Section 1.1). Following that, the aim of the study is defined. Section 1.2 defines the term iMMS. Section 1.3 explains the structure of the paper.

\subsection{Relevance and Aim}

Smart and individualized products have become very popular and are in high demand for various industries [1-3]. Micro-mechatronic systems (MMS) are key enabling technologies for the development of smart products, such as intelligent telephones, intelligent sensors for machines and plants or micro robots. Yet, these only represent a very small selection of such applications [4]. The European Commission expressed the importance in a strategy excerpt that MMS are not only essential to digital products and services, but they also underpin innovation and competitiveness for all major economic sectors $[5,6]$. However, the increasing demand for individualization poses great challenges to the engineering of MMS, as the entire MMS manufacturing process is based on the concept of large-scale production [7]. The reason for a large-scale production strategy is that MMS are often components of standardized mass products such as smartphones, automobiles or computers $[4,8]$. Now, with the increasing demand for individualization, a 
growing demand can be assumed for the embedding of MMS into individualized products or individual assembly spaces to make these products smarter or give them additional functionality. Some examples of individualized MMS (iMMS) can already be shown in areas of mechanical engineering and medical technology, in which individual components of MMS are used and needed [9-11]. A typical fabrication technology for iMMS are molded interconnect devices (MID), also named mechatronic integrated devices, due to their high potential for functional integration, miniaturization and especially design flexibility [12]. MID are often applied in size-critical applications [13]. To ensure cost-efficient and individualized MID production, one approach is to redesign established process chains and use digital process chains such as additive manufacturing technologies [14]. A digital process chain can be defined as a manufacturing chain that includes digital manufacturing technologies (DMT). DMT are characterized by the fact that conventional manufacturing technologies are combined with digital techniques [15]. However, there are few cases that emphasize the challenges of developing and producing iMMS with a digital process chain. So, there is a lack of knowledge about the engineering design process (EDP) within the context of iMMS. To meet the requirements such as time, cost and quality, development methods and adapted development processes can help achieve the requirements.

The general relevance of using methods and tools within the development and planning stage is well known [16]. This could play a greater role for iMMS, as these products are highly dependent on technologies and need to fulfill various requirements such as time, cost and quality. Gausemeier et al. [17] also describe the need for new approaches in product development, in particular for intelligent technical systems, which are always based on MMS. There is a gap between complexity in product and production on the one hand and performance of the product development in industrial practice on the other hand. This gap seems to be widening.

The aim of this study is to develop a case-based methodology that supports the creation of an EDP for iMMS by identifying needs for product development methods within the EDP. The research objectives are reached through empirical studies such as expert interviews and case studies.

\subsection{Definition of $i M M S$}

A new definition for iMMS is noted in this section. The term personalization is considered a synonym for individualization. Koren et al. [18] define mass individualization as follows: "In the mass-individualization paradigm the customers are involved in the design process! This is a new challenge of this paradigm. In mass-customization even if some customers feel as if they are designing their product, the truth is that they are NOT involved in the design of their products. They are simply selecting an option." With this definition, it becomes clear that individualization focuses on customer-related development activities in order to create a higher added value for customers. In addition, the distinction from mass production becomes clear by this definition.

In this paper, the term MMS is used as defined by Schwesinger et al. Accordingly, MMS are very small components that, in the best case, combine sensors, electronic processing of data and physical action (actuators) [19]. Consequently, an iMMS can be defined as follows: An iMMS is an MMS that consists of a limited number of components. At least one of them is unique in terms of geometric shape and/or electrical or mechanical function.

\subsection{Structure}

Section 1 contains the relevance and motivation of this paper. Section 2 gives a brief overview of related work in this field and uncovers areas where more research is needed. Section 3 describes the research design and the development of the TEDP-Methodology. In Section 4, gained results are overviewed. In Section 5, the results are discussed. The last section provides a short summary and suggests further research. 


\section{Literature Review and Research Question}

This section will present, first, an overview of MMS in the context of individualization and, second, tailoring of the EDP.

Micro-mechatronics deals with the fabrication of integrated, movable microstructures with electronic components within a $0.1-1000 \mu \mathrm{m}$ size range [20]. Another field of MMS is system integration. This means the connection of different MMS components to a complete intelligent system [21,22], whereby the complete system exceeds the micro range, for example, intelligent individual implants in medical technology or intelligent connecting elements in the industrial sector with individualized geometries. The latter is demonstrated in this article in detail as a real case study. Within the many advantages achieved through MMS, their main and most important feature lies in miniaturization [21,23]. In order to meet this purpose and to be able to offer a high degree of freedom when it comes to designing complex products, MID technology is recommended [24-26]. Furthermore, MID offers various technological features that go beyond classical printed circuit board (PCB)-based assemblies. Therefore, this technology should be described in more detail as follows.

MID are generally defined as injection-molded plastic substrates that contain conductive circuit patterns and integrate both mechanical and electrical functions [12]. In combination with laser direct structuring (LDS), MID offer the possibility to design electrical and mechanical components on three-dimensional surfaces to increase functionality and integration levels and to reduce costs. For example, transmission lines, antennas, switches and connectors can be integrated on carriers such as the covers of mobile phones or the housings of car wing mirrors $[27,28]$. In contrast to classically manufactured electronic assemblies, MID technology enables the functionality of the entire component through freedom of design [24-26]. MID can be geometrically classified into four categories: 2D (planar process surface), 2.5D (plane-parallel process surface), $\mathrm{n} \times 2 \mathrm{D}$ (process surfaces in angular position) and 3D (free-form surfaces, ruled surfaces) [12]. Thus, MID technology is a suitable technology for iMMS. However, the main and starting process of MID for manufacturing the 3D substrate is the injection-molding process [12,25]. Due to the injection-molding process, cost-intensive tools must be manufactured. These costs cannot be defrayed for small batch sizes, and thus, the use of MID is not economically feasible for individualized MMS. Consequently, it is worth considering the application of DMT, such as rapid tooling. There are very few rapid tooling application examples for the production of MID [29]. This is probably why there is a lack of an EDP within the context of iMMS based on MID technologies. However, a contextual EDP is an important requirement for successful project management [30-32].

There are various sources available that discuss the influence of relevant contextual factors within the EDP. It is generally recognized that there is a need to adapt a process model such as an EDP to the circumstances of a project or other contextual factors [32-39]. Therefore, several papers that deal with the contextual adaptation of the EDP can be found. Hollauer and Lindemann give a general overview of existing tailoring approaches [40]. From this overview, one can conclude that the relevant approaches to support process tailoring are mainly in the field of software engineering. Thus, Hollauer and Lindemann suggest that a tailoring approach for interdisciplinary engineering design is desirable [40]. In addition, only one tailoring approach could be identified that is based on case studies. This approach, by Park and Bae, is also specialized for software engineering [41] and uses the case-based reasoning (CBR) technique to tailor software development projects. A CBR technique is used to find structural similarities with different characteristics [42]. The study by Park and Bae combined the CBR technique with process slicing to identify the process elements that are to be tailored. It consists of the steps used for generating a preliminary process slice, retrieving the most similar case applicable to the preliminary process slice and obtaining the final process slice using the retrieved case. However, the proposed approach is exclusively made for reducing the effort and errors during process tailoring for a large-sized software process; hence, it is focused on software development projects. 
There are also approaches that deal with modeling or describing the context of specific development projects by identifying influencing factors, tailoring criteria, or determining project characteristics, e.g., the study by Preez et al. [43]. All approaches mentioned above were designed to configure project-specific development processes. Regarding MMS, there are also adapted EDP such as EDP for MMS [44] or an integrated process modeling and planning of mechatronic products [45]. However, a generally applicable and rule-based approach to the adaptation of an EDP has not been given sufficient consideration and the individualization aspect has not been taken into account so far.

All this leads to the following research question: How can a methodology be developed to tailor a reference process for engineering design that takes into account case studies that are methodologically abstracted and contextual factors that are empirically analyzed, whereby the described methodology can be illustrated by an example of an iMMS? A further question is: What are specifically the critical points within the EDP for iMMS?

\section{Research Design and TEDP-Methodology}

The research design of this paper is based on the design research methodology of Blessing and Chakrabarti, which consists of four stages: research clarification, Descriptive Study I, prescriptive study and Descriptive Study II [46]. Figure 1 shows the used research tools and the main results for each research stage, which are contained in the respective sections.

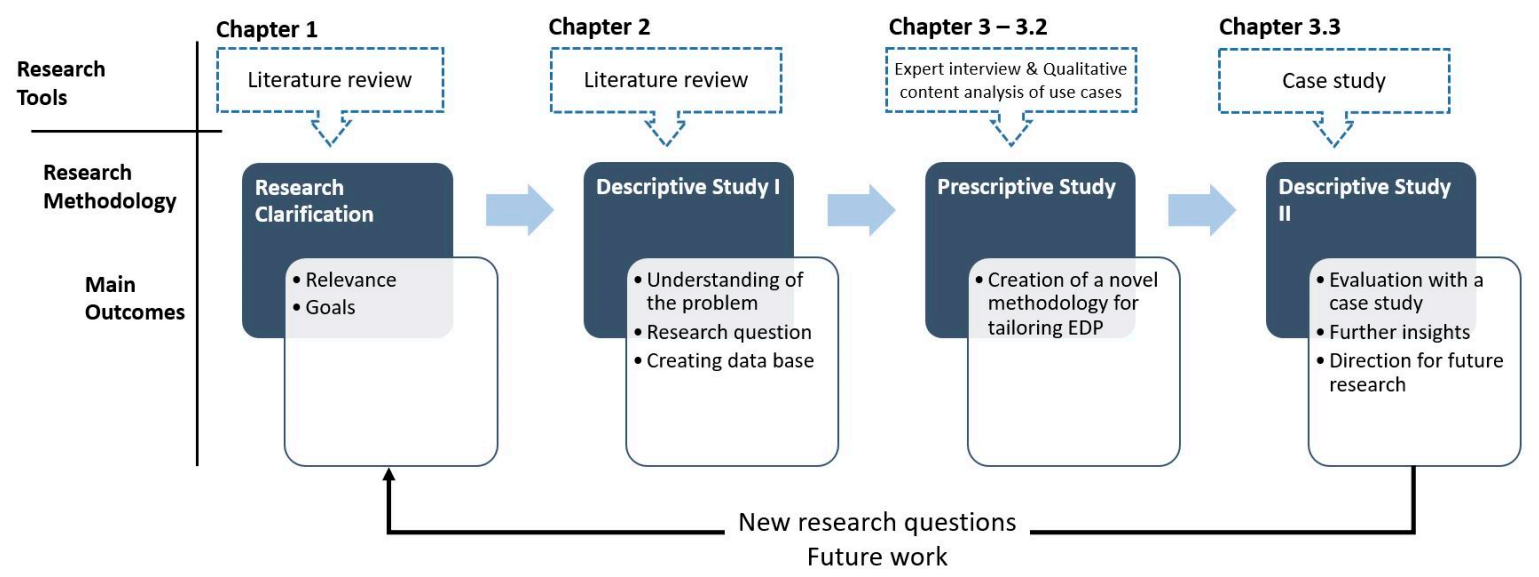

Figure 1. The used design research methodology.

\subsection{Approach to Identify iMMS Use Cases}

Before one can classify use cases, they must be identified. The user goal technique (UGT) is suitable for this purpose [47]. The UGT enables the identification of use cases through a series of specific questions to the (potential) user that identify the tasks that users would like to accomplish with the help of a system. This technique is typically used in interviews when gathering requirements from users. In the scope of this paper, qualitative interviews were conducted following the UGT. Instead of specific questions, requests were made to create possible use cases. Before that, the corresponding technologies and examples of iMMS were explained. This also allowed participants who were not specialized in MMS to create a use case.

Participants were 17 experts, including scientists, product managers and general managers, from different areas of industry and research. This composition was chosen to represent the widest possible range of use cases, as iMMS are conceivable for all possible use cases and represent an interdisciplinary domain. Each interview lasted about 30 to $50 \mathrm{~min}$. The interview included the following steps: 
1. Welcoming the interviewee and introducing the underlying definition of iMMS.

2. Presentation of some examples of iMMS, which were manufactured with the help of MID technologies and additive manufacturing technologies.

3. Participants write or explain a detailed use case for their area under consideration of the above-mentioned points ( 1 and 2 ).

4. Participants explain or write the goals and requirements of their created use cases.

With the conducted expert interviews, four new use cases and four of the most important requirements for the development and manufacturing of iMMS can be analyzed. Another two use cases were already known, as these two use cases were carried out by our research institute in co-operation with the industry. In order to cover more use cases and eventually derive new product groups, these two existing use cases were also integrated. Consequently, six use cases were collected (see Table 1), and these can be used for the methodology. To ensure that all information from interviewees was considered and to avoid an increase in complexity for the interviewers when explaining a use case, use case diagrams such as the unified modeling language (UML) were not used. In addition, the UML cannot specify interaction requirements where the system should initiate an interaction between the system and an external actor [48]. However, this aspect could be of great importance for the later creation of an EDP. Therefore, the collected use cases were in a large unstructured text file and did not have a predefined format. To overcome this issue, qualitative content analysis was applied.

Table 1. Paraphrased use cases.

\begin{tabular}{|c|c|}
\hline Number of Paraphrased Use Cases & Paraphrased Use Case \\
\hline PUC 1 & $\begin{array}{l}\text { Earmold with micro-electronics for permanent, non-invasive blood pressure } \\
\text { measurement at the ear. Therefore, it must be biocompatible and comply with Directive } \\
\text { 90/385/EEC with risk class IIa. This is helpful for stress-free long-term measurements } \\
\text { of blood pressure and, thus, represents an enormous advance for the diagnosis and } \\
\text { therapy of patients with cardiovascular diseases. }\end{array}$ \\
\hline PUC 2 & $\begin{array}{l}\text { Monitoring and modernization of special-purpose machines for testing and measuring } \\
\text { of gears by using sensors. There are many disturbance variables such as vibration and } \\
\text { dust. High accuracy and reliability are required for the optical sensor to identify cracks } \\
\text { in the tooth flanks. }\end{array}$ \\
\hline PUC 3 & $\begin{array}{l}\text { Detection of temperature, humidity or light irradiation with direction-related sensor } \\
\text { information. Individual room situations can be optimally detected via an individualized } \\
\text { sensor carrier. }\end{array}$ \\
\hline PUC 4 & $\begin{array}{l}\text { Slope measurement for special shipping containers with highly sensitive goods, as well } \\
\text { as real-time monitoring of } \mathrm{CO}_{2} \text {, oxygen concentration and humidity in the container. }\end{array}$ \\
\hline PUC 5 & $\begin{array}{l}\text { Voltage and energy measurement of a test vehicle in pre-series development. The } \\
\text { sensors must withstand many disturbances such as vibrations and temperature } \\
\text { differences at the engine or at the high-voltage battery. At the same time, the sensor } \\
\text { module should be as small as possible, since the free space on the car's power unit is } \\
\text { very limited. }\end{array}$ \\
\hline PUC 6 & $\begin{array}{l}\text { Temperature and humidity measurements with a smart M8 connector that is based on } \\
\text { the industry standard. This connector should be installed exactly where it is needed. } \\
\text { The data are sent to a mobile device via a standard Bluetooth module. The connector } \\
\text { should have enough features to be usable by early customers and will later go into mass } \\
\text { production. }\end{array}$ \\
\hline
\end{tabular}

\subsection{Categorization of the Use Cases with Their Requirements}

The outcomes of the expert interviews are categorized in this section, and the additional collected requirements are considered in the categorization. Qualitative content analysis with inductive category development, according to Mayring, is appropriate to categorize expert interviews and is used for this purpose $[49,50]$. The main goal of qualitative 
content analysis is to reduce the extensive text material to a manageable size while ensuring that important information is not overlooked [50]. The inductive category development in this paper contains five steps that are inspired by Mayring's approach. The first step is the clarification and definition of the research question that was created in Section 1 by using the literature review. The second step determines which content needs to be categorized. This step was conducted in the previous section. The third step paraphrases essential text parts. For this, paraphrasing rules must be determined. According to these rules, evaluative utterances and redundant terms are eliminated and only substantive understanding of the terms is considered. The paraphrased use cases (PUC) are shown in the following.

The fourth step is the reduction and abstraction of the paraphrased texts. To conduct this, abstraction rules are necessary. Mayring mentions that there is not a standard procedure for this step [50]. Therefore, in this step new approaches are integrated. For the abstraction, approaches from the discipline of cognitive linguistics will be used. Class inclusion is one of these approaches and defines that objects can be classified into two or more categories at the same time [51]. This means that features of subordinates are included in its superordinate. Thus, class inclusion is a structural principle for categorization. It, thus, implies that the superordinate and its abstract entities include subordinates and its specific entities. In order to obtain a higher level of superordination, the PUC will be superordinated through determined attributes (Figure 2). This raises the question of which attributes can be used for superordination. As these are use cases, the typical characteristics of a use case should be applied. These characteristics can be derived from the general definition of a use case. Jacobson is known as the inventor of use cases and use case modeling. He defines a use case as a set of ways to use a system to achieve a particular goal for a particular user. Taken together, the set of all use cases is a combination of all the useful ways to use the system and illustrate the value it will provide [52,53]. Within this definition, a use case can also be interpreted as a sequence of interactions between one or more actors and a specific system that results in an assessable outcome of value to one or more stakeholders. From this, three attributes can be selected from a use case, namely, a "sequence of interaction", "actors" and a "system". If these attributes are applied in the analyzed use cases of iMMS, three specific attributes are derived for the superordination and the categorization of the use cases of iMMS. These are:

- " "Area of application" through the derivation of "actors";

- "Function" by deriving "sequence of interactions";

- "Product" by deriving "systems".

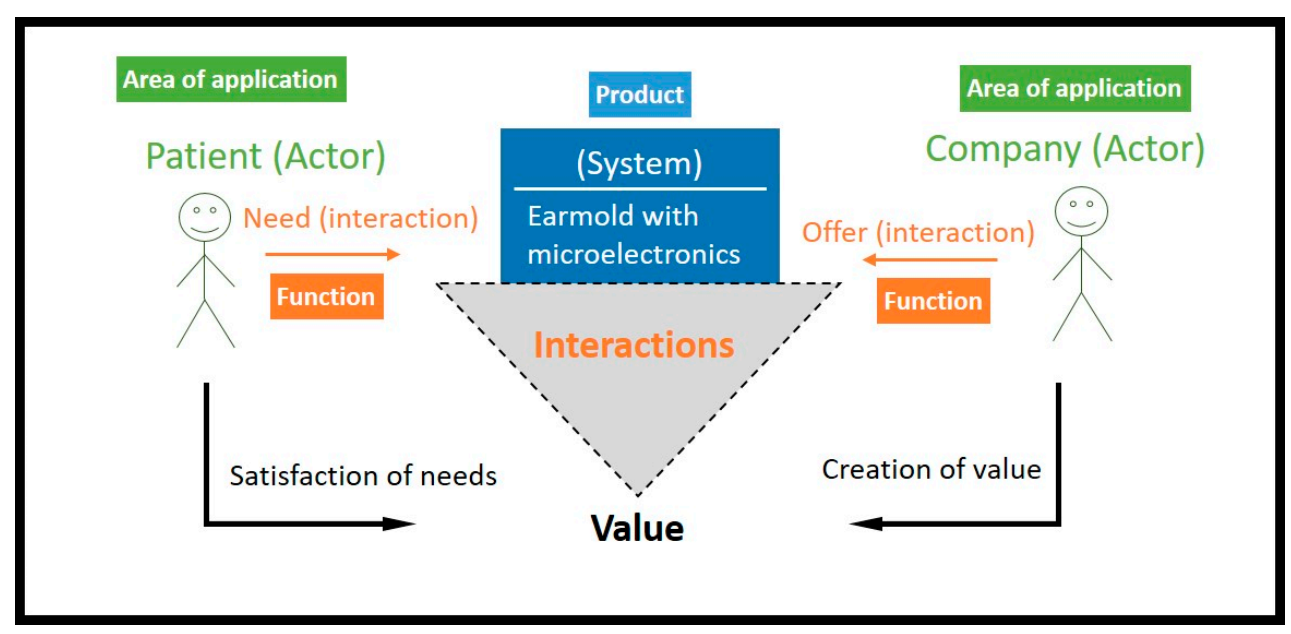

Figure 2. Derivation of specific attributes to categorize the use cases of iMMS. These are "area of application", "product" and "function". 
This derivation of the three special attributes is illustrated in simplified form by using PUC 1 as an example (see Figure 2).

By doing this, it is possible to systematically conduct the reduction and abstraction of the PUC. Table 2 shows the reduction and abstraction process.

Table 2. Qualitative content analysis of the PUC with the derived attributes-area of application, product and functionswith one example in Line 2.

\begin{tabular}{|c|c|c|}
\hline Paraphrased Use Cases & Reduction 1 & Reduction 2 \\
\hline & & Abstraction Level \\
\hline PUC $x$ & $\begin{array}{l}\text { Abstraction of PUC based on the derived } \\
\text { attributes. }\end{array}$ & $\begin{array}{l}\text { Abstraction of Reduction } 1 \text { based on the } \\
\text { derived attributes. }\end{array}$ \\
\hline $\begin{array}{l}\text { Earmold with micro-electronics for } \\
\text { permanent, non-invasive blood pressure } \\
\text { measurement at the ear. Therefore, it } \\
\text { must be biocompatible and comply with } \\
\text { Directive } 90 / 385 / \text { EEC with risk class IIa. } \\
\text { This is helpful for stress-free long-term } \\
\text { measurements of blood pressure and, } \\
\text { thus, represents an enormous advance for } \\
\text { the diagnosis and therapy of patients } \\
\text { with cardiovascular diseases. }\end{array}$ & $\begin{array}{l}\text { Customized and functionalized orthoses } \\
\text { on a high-risk patient to measure vitality. }\end{array}$ & $\begin{array}{ll}\text { - } & \text { Medical industry } \\
\text { - } & \text { Highly individualized products } \\
\text { - } & \text { with MMS } \\
\text { Measuring on the human body }\end{array}$ \\
\hline$\ldots$ & $\ldots$ & $\ldots$ \\
\hline
\end{tabular}

Table 2 shows both a maximum necessary detailed view by the PUC and an abstracted view by Reduction 2 that establishes a basis to categorize the collected use cases. This presented approach allows collecting and allocating requirements to the respective use cases. Product and manufacturing requirements are among the most important influencing variables for the EDP, which are, therefore, among the most important criteria for creating or tailoring an EDP [54-57]. Through the conducted expert interview in Section 2, requirements and their importance were also surveyed. Accordingly, in the last and fifth step, the assessed requirements should be integrated into the reduction process. By doing this, a categorization of iMMS based on use cases in order to review and tailor pre-existing EDP, will be ensured.

The main requirements for iMMS are specified in the following:

- $\quad$ Production time;

- Reliability;

- Costs;

- $\quad$ Batch size.

In order to ensure objectivity in the evaluation of the requirements and to avoid a central tendency error, a list with an explanation of the levels was created. This list is shown in Table 3.

Table 3. Explanation of the assessment and list of the general requirements.

\begin{tabular}{ll}
\hline List of the Main Requirements for iMMS & Explanation of the Assessment \\
\hline Relevance of production time (pt) & High $\leq 3$ months, medium $=4-6$ months, low $=7-12$ months \\
\hline Relevance of reliability (r) & $\begin{array}{l}\text { High = harm to people, medium = high financial damage of property, } \\
\text { low = minor damage of property }\end{array}$ \\
\hline Relevance of costs (c) & $\begin{array}{l}\text { Low }=\text { Costs of the MMS are a lot higher than the final product, } \\
\text { medium = Costs of the MMS are more or less the same as the final } \\
\text { product, high = Costs of the MMS are a lot less than the final product }\end{array}$ \\
\hline Planned batch sizes (bs) & Low $=1-20$ pc., medium $=21-500$ pc., high $>500$ pc. \\
\hline
\end{tabular}


With the steps shown above, characteristic product groups for iMMS can be created. Consequently, the EDP can be adapted and tailored to the created product groups. So, the methodology can be defined as follow: Qualitative content analysis + Assessments of the requirement $=$ Product groups (see Table 3 ).

Figure 3 shows the logical approach of the methodology. With this, product groups are characterized and can be traced back quickly and easily. These are, for example, that the costs and the batch size play an eminent role for this product group. The characteristics of the analyzed product groups are important influencing factors for the EDP. Therefore, it is important to create product groups for production processes and for tailoring of an EDP.

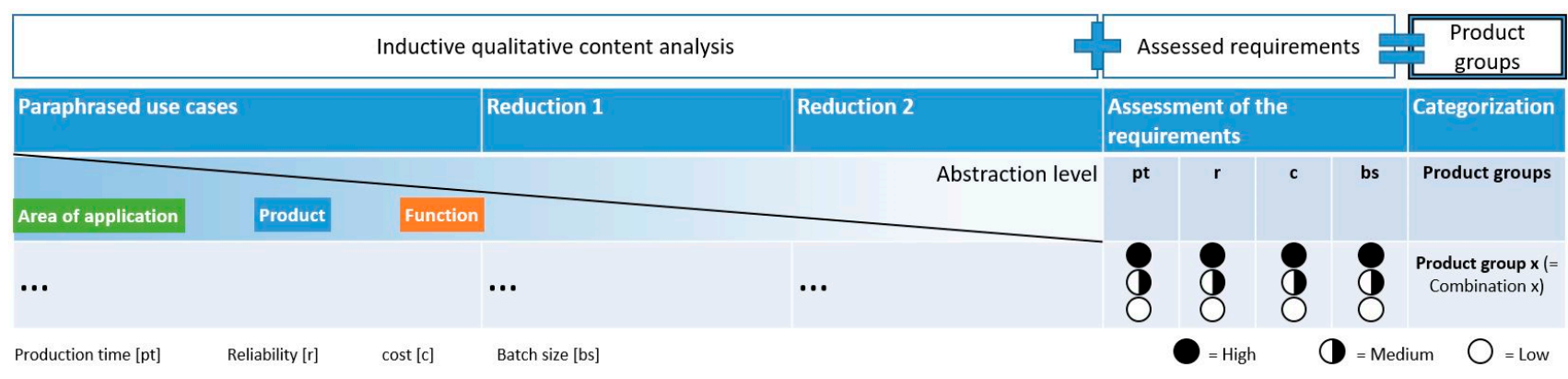

Figure 3. Short excerpt of the inductive categorization of use cases with requirements to create product groups (methodology).

\subsection{Real Case Study}

In order to find a suitable reference process for iMMS from the variety of available reference processes for product development, which then can be adapted more precisely to the respective analyzed iMMS product groups, a real case study is presented in this section. Additionally, this case study validates the conducted methodology in Section 3.2.

Case studies constitute an appropriate empirical investigation for decision problems [58,59]. It is, therefore, intended to conduct a case study for decision making in order to find suitable reference processes. Section 1 shows that MID and DMT are appropriate for the manufacturing of iMMS. Therefore, these technologies are considered and in use. These technologies enabled manufacturing an iMMS according to the definition in Section 1, as illustrated in Figure 4.

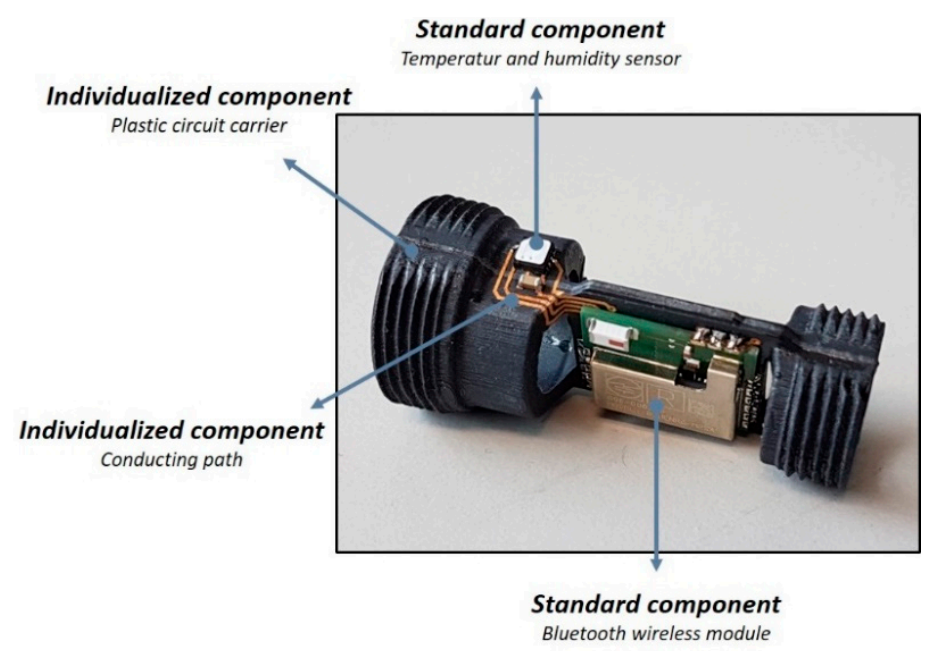

Figure 4. Smart connector as iMMS.

In this case study, PUC 6 is considered because, in this use case, the product is very complex and requires several manufacturing technologies. The complexity of this product is confirmed by the fact that there are very few soft tooling applications that include 
undercuts. The soft tooling consists of four components, which are injection mold, ejector mold and two different slides (see Figure 5).

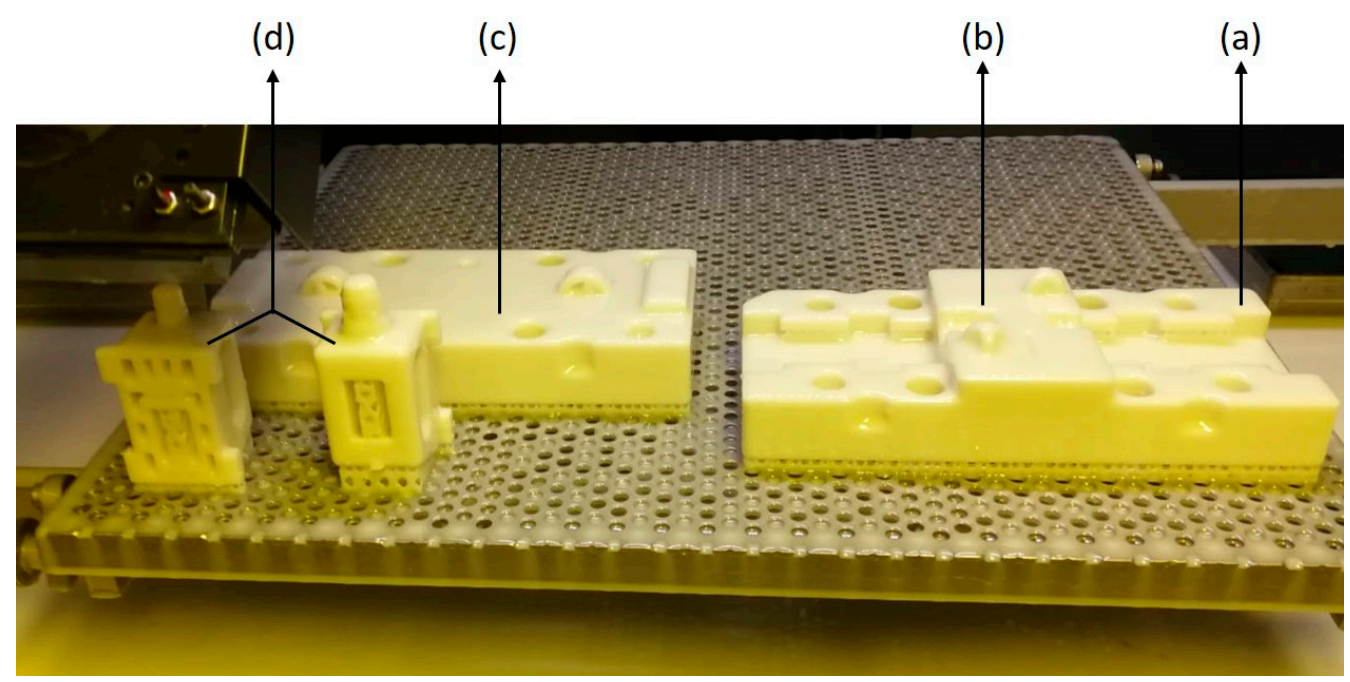

Figure 5. Overview of the soft tooling components that are printed with digital light processing (DLP): (a) ejector mold; (b) cavity; (c) injection mold; (d) slides M18 and M14.

The project was carried out in co-operation with a company that develops and distributes high-quality connectors worldwide. The goal is to develop and produce an intelligent electrical connector with contacts on the input side and a substrate that was customer-specifically and individually developed. The idea and aim are to produce rapidly for early customers who can then provide feedback for serial production. In order to be able to validate the feasibility of series production at an early stage, it makes sense not to print the component directly (rapid prototyping or direct manufacturing) but to use an additively manufactured tool insert (soft tooling). That way, the injection-molding process can be validated, and failure costs in the subsequent production of steel tools can be avoided (see Figure 6).

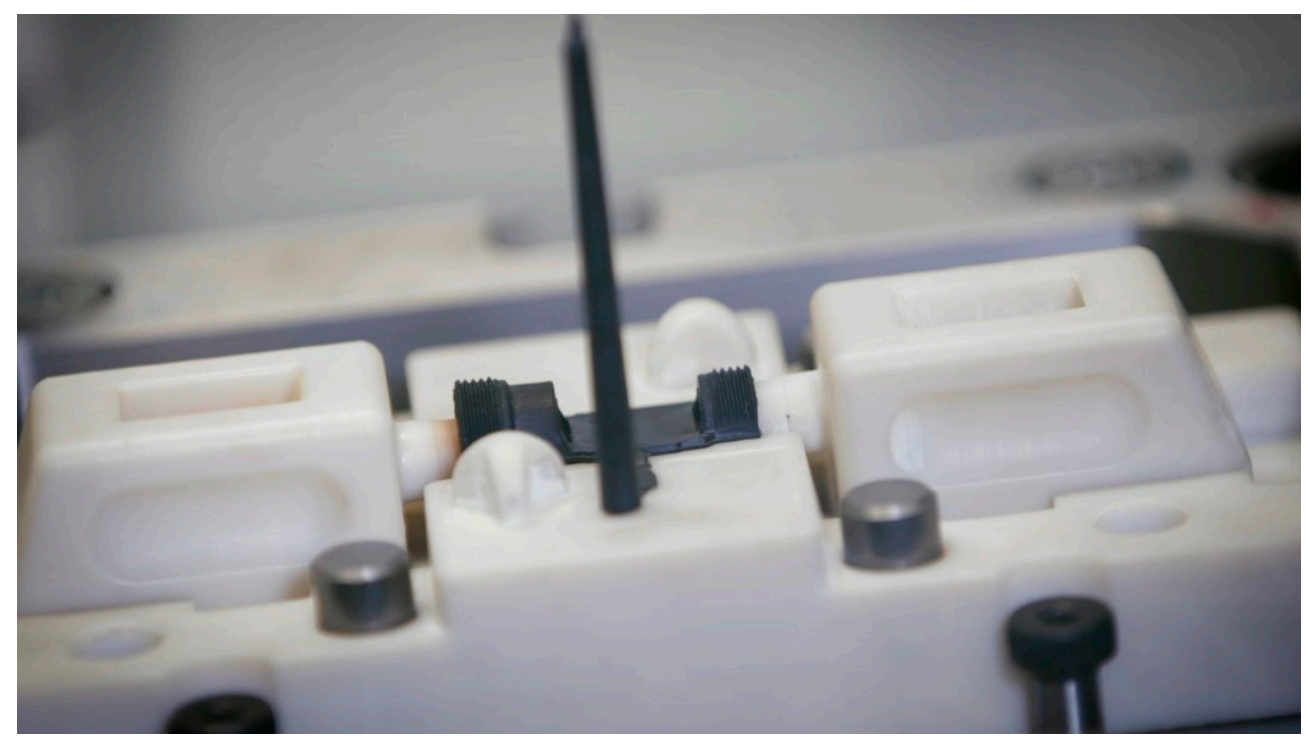

Figure 6. In-process injection molding with soft tooling with slides.

Before establishing the EDP for new products, it is important to obtain market insights regarding customer demands. The co-operating company found out, from its own market analysis, that real-time monitoring of physical variables is more and more important 
for customers. Beyond this market analysis, Section 1 underlines the relevance of smart systems. After ensuring the demand, the development process starts. The EDP started with the idea stage, which was supported by brainstorming and design thinking techniques. After the idea stage, the project leaders who know the customer and market requirements defined specific requirements. These two stages were conducted with employees from the middle and senior management. This took about five working days. The next step consisted of the system design also called "conceptualization" or "cross-domain solution concept". In this step, for the first time, the involvement of all disciplines (micro-electronics, micro-mechanics, informatics) is required. As there were adaptations and suggestions from each domain, primary ideas and requirements had to be adapted. This caused high costs and time delays already at early stages. Most of the adjustments and suggestions were made in order to manufacture more reliably and efficiently. It was obvious that the suggested alternative solutions from each department were more economical and efficient and still met the requirements. The next step was domain-specific design and modeling. At this stage, the developer carried out detailed work, mostly focusing on each domain separately. The next step was system integration, which means that the outcomes from the different domains were integrated into an overall system. In this step, one challenge was to work with 2D design tools as well as with 3D design tools, as fully matured 3D design software solutions do not exist yet [60]. Therefore, different software solutions had to be applied, which complicated the integration of the assemblies from different disciplines. This means that in this project, Creo, AutoCAD and Eagle were used separately. Figure 7 gives an overview of these steps.

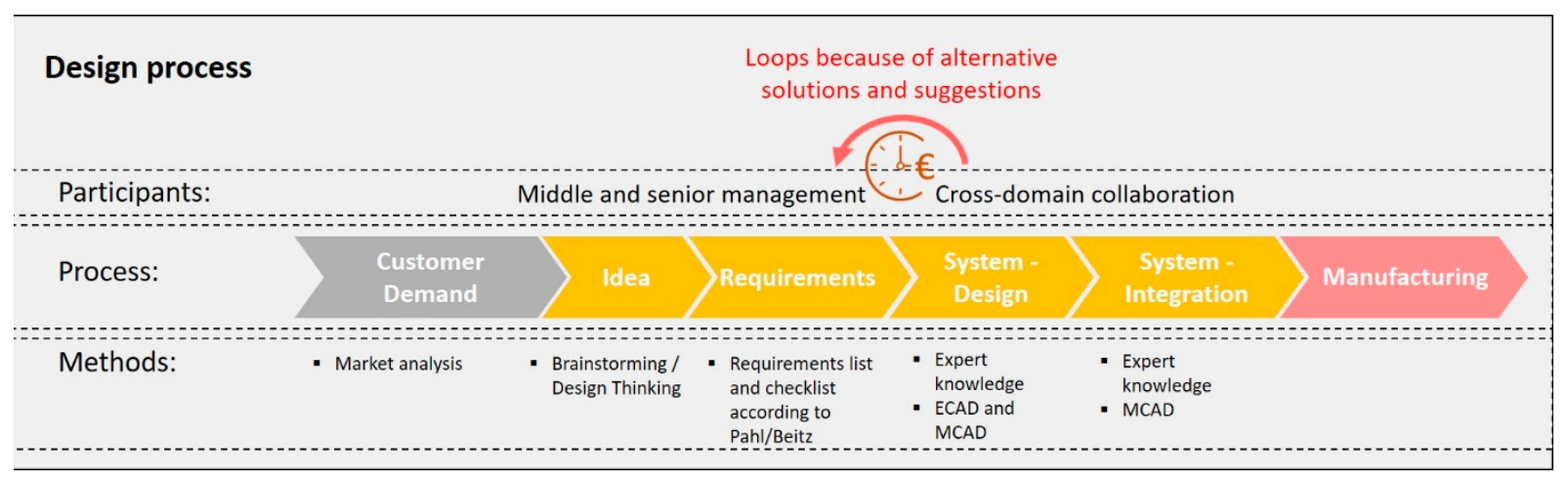

Figure 7. Overview of the design process for PUC 6 with the used methods and participants.

From this phase, the manufacturing process starts. Figure 8 shows the manufacturing process chain with the related technologies. Injection molding is marked because it is only used for certain use cases such as PUC 6. Some correction loops were also carried out during the manufacturing process. The reasons for these correction loops were the individuality and complexity of the component and the missing empirical values for the machine parameters with soft tooling, which is why defective components were also produced. The assembly was carried out manually due to the small batch size. An automated assembly would have also been possible but the planning for this automation process would have cost more time than the manual implementation. After these steps, reliability analysis was completed based on the defined requirements. Thereby, no bugs and defects were found. Simultaneously, the framework for the Bluetooth radio module was coded with the emBitz development environment, and the arm cortex $\mathrm{m} 0$ architecture was used. A universal Windows application was used for the implementation. The software implementation took about two working days. The installation of the software into the smart connector took $1 \mathrm{~h}$, testing included. 


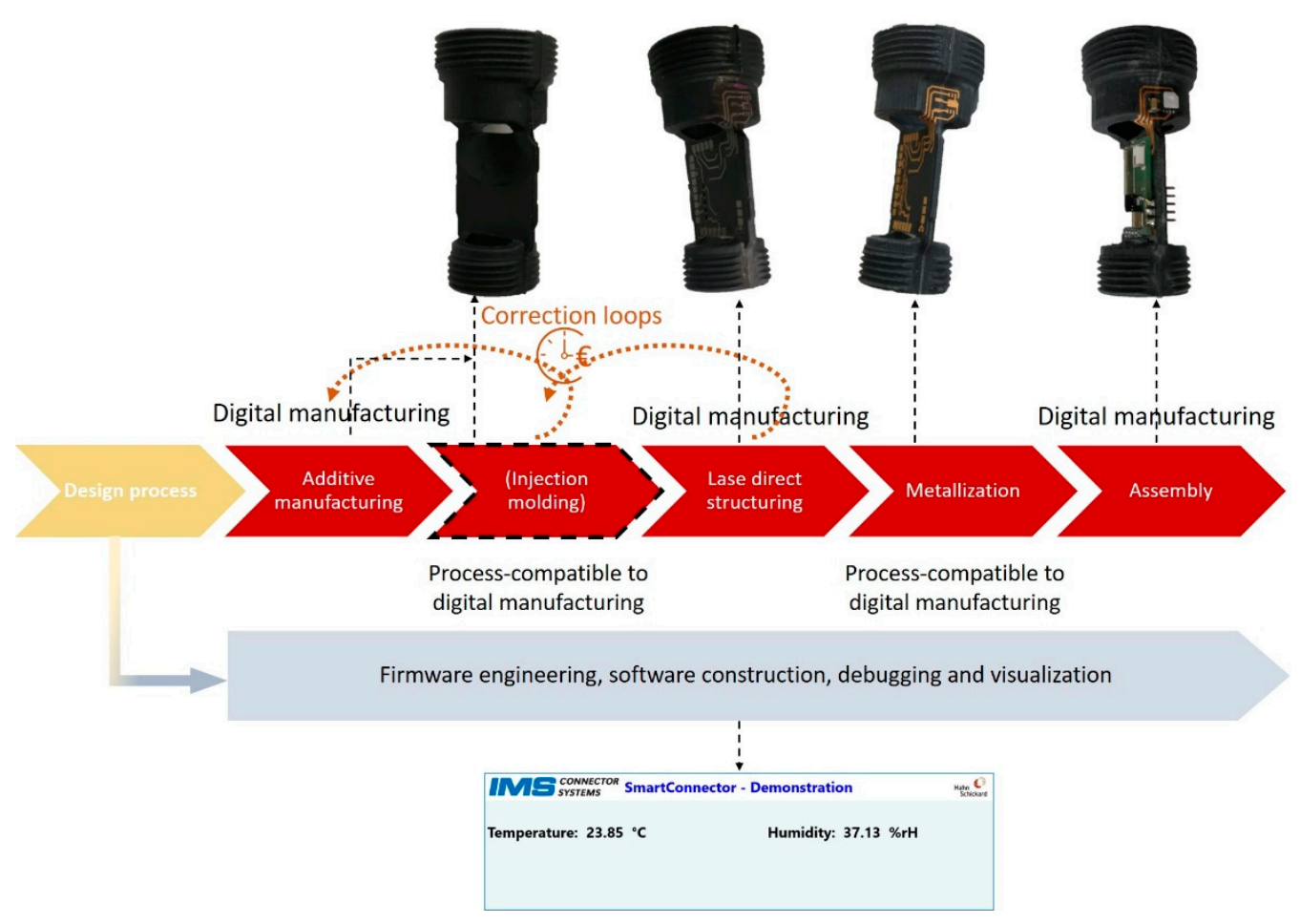

Figure 8. Implemented digital manufacturing process chain for iMMS.

The whole development phase took about nine working days, and on average, six employees were needed. The manufacturing phase required six working days with five employees. Figure 9 shows the final product used as the minimum valuable product (MVP) for the co-operating company.

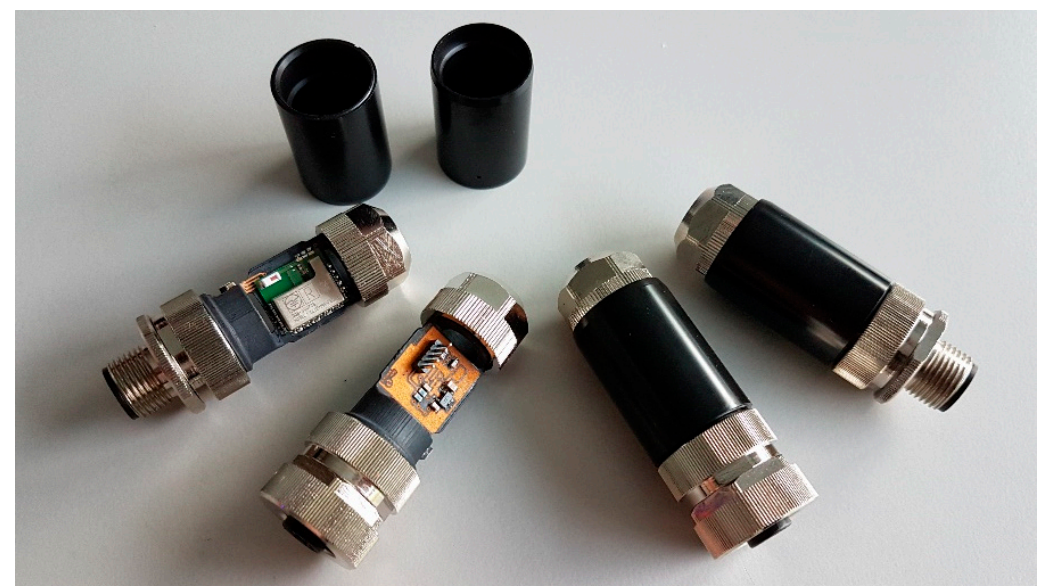

Figure 9. Final product in which the iMMS is integrated.

\section{Implementation and Results}

This section implements the methodology presented in Section 3 and summarizes the findings. In Section 3, the novel TEDP-Methodology was created with the aim and focus to categorize the use cases into product groups. For this purpose, various approaches were used. The implementation of the TEDP-Methodology is shown in Figure 10. 


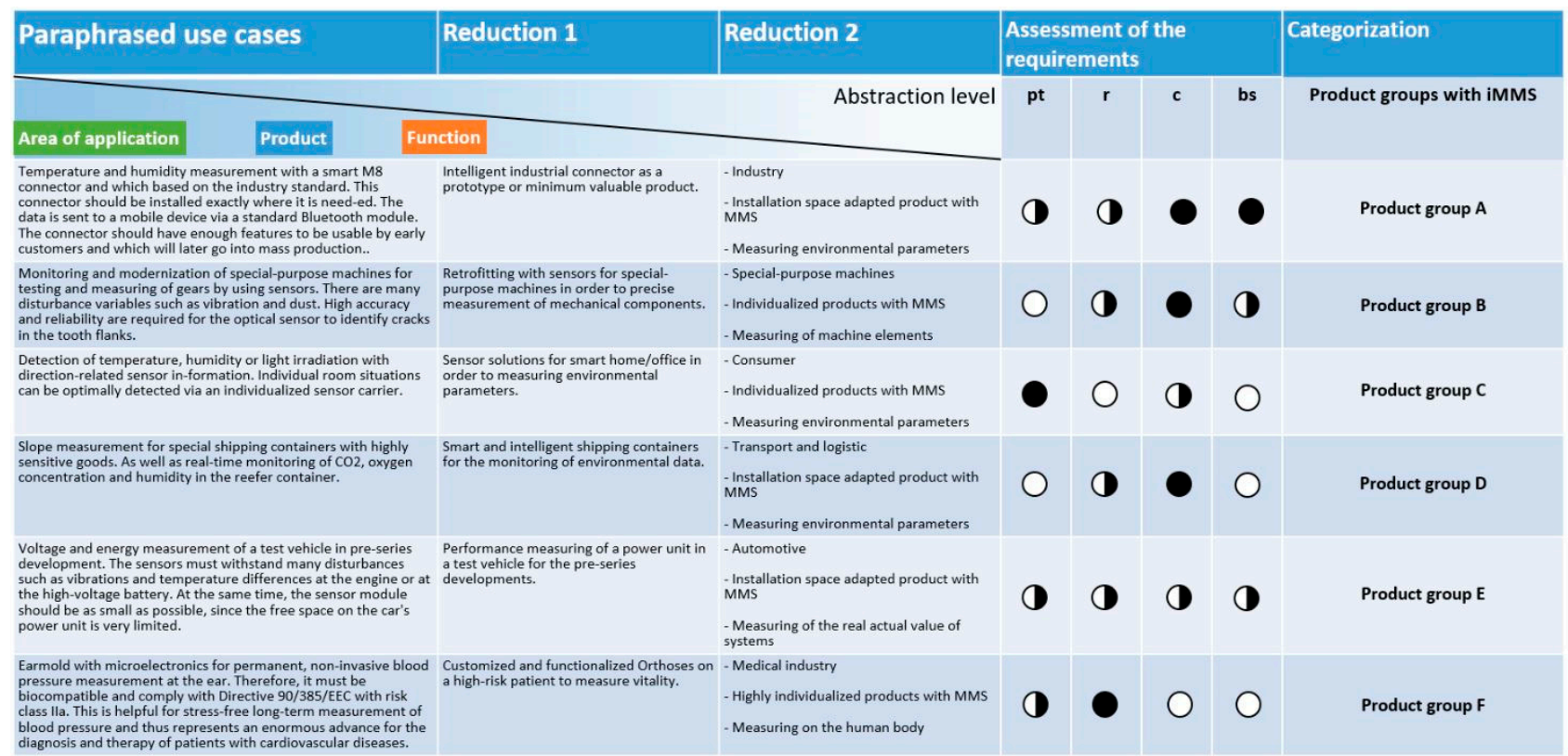

Figure 10. Inductive categorization of all analyzed iMMS use cases under consideration of requirements to create product groups.

The results in this section provide the fundamentals for a use-case-based EDP in the engineering area of MMS. They show that there are use cases for iMMS. Consequently, the trends and the relevance mentioned in Section 1 are also confirmed. The results also show that iMMS can be used for different branches of industry. Further results from Section 3.2 are the definition of the requirements for iMMS. This was shown in Table 3.

From these results, it is clear that the importance of the requirements strongly depends on the individual use case, although it is always based on iMMS. This is the reason why each use case has to be attributed to a different product group, and no group of use cases within the same product group has emerged from this study. The tailoring of an EDP for iMMS is more difficult due to the diversity of product groups, as this would require tailoring a separate EDP for each product group. In order to create a general EDP for all iMMS, it is sensible to give all requirements a high weighting. Then, this would be the most demanding case. That means that the requirements "production time", "reliability" and "costs" can be ranked as having the highest relevance. For the requirement "batch size", it is sensible to set both high and low, as both strategies can require high engineering demands. By using this approach, a fictitious product group is used to create an EDP and this EDP meets all requirements. Another approach is to prioritize the evaluation that emerged from this study. By doing so, it becomes clear that costs and reliability would need the highest priorities. In summary, this new methodology provides an overview of the diverse characteristics of product groups. These characteristics are important influencing factors for the design process and, therefore, helpful when a design process is newly created or tailored.

In Section 3.3, a use case for iMMS was implemented, and the design and manufacturing process was observed. The goal was to test and confirm the manufacturability of complex iMMS with DMT and to find a reference process that is similar to the conducted design process. The gained insights and results of the case study are as follows:

1. The implemented design process for the smart connector is similar to V-ModelGuideline 2206 for mechatronic systems of the German Association of Engineers (VDI) but not transferable without modification [61].

2. The development and manufacturing of iMMS with digital technologies in a short time (approx. 15 working days) are possible.

3. In both the design process and the manufacturing process, cost-intensive revision loops had to be executed. 
4. There is a need for methodological support within the design process, especially in the area of manufacturability, reliability and CAD software tools.

5. Expert knowledge plays a very important role in the effective development and production of iMMS.

Based on the first result, it can be assumed that the V-model is the basis for tailoring and creating a new EDP for iMMS. Nevertheless, VDI 2206 cannot be transferred one by one, as gaps have been identified. Additionally, a model as abstract as VDI 2206 cannot meet the specific requirements of the iMMS. For example, there is no reference to crossdomain work during the planning and defining of requirements. Furthermore, in the VDI 2206 guideline, corrections and verifications are only carried out during system integration, although this can already be important during the definition of requirements. Furthermore, the commonly existing design processes always assume that prototypes are manufactured. However, for individualized products and especially for iMMS, this is more cost-intensive and time-consuming than for mass products. This reinforces the need for a tailored EDP. Further results show deficiencies and optimization potential within the design process. These results provide new reference points in further research, especially for the area of design engineering.

\section{Discussion}

From the literature review, it was shown that the combination of the two technologies, MID and rapid manufacturing, is a promising approach for the manufacturing of iMMS. However, there is a lack of development processes and tools that would ensure support for the development of iMMS. Furthermore, it could be shown from the literature review that there is also a lack of a systematic approach to context-specific tailoring based on use cases. Based on this literature analysis, a new approach could be examined and developed.

The findings show that the rule-of-ten cost curve concerns iMMS in particular. Hence, there is a reason to believe that the cost curve is even steeper. It is, therefore, even more important to apply product development methods for iMMS. Past findings show that the development of iMMS requires specialized knowledge. Hence, the use of an engineering tool in the context of iMMS can be of great help in that process. In the following, the research questions (RQ) presented in Section 2 shall be discussed:

(1) "How can a methodology be developed to tailor a reference process for engineering design that takes into account case studies that are methodologically abstracted and where contextual factors are empirically analyzed?"

(2) "What are specifically the critical points within the EDP for iMMS?"

RQ 1: By asking experts and users for possible use cases and requirements and using Mayring's qualitative content analysis, a new tool to tailor EDP can be developed. This method will make it possible to create product groups based on user cases. These product groups can then be used to build/create an EDP. The product groups consist of contextual factors that are essential and crucial for a new EDP. As a result, this method proves to be useful for an EDP that aims to develop new (types of) products. Yet, there are weaknesses of the method, which shall be mentioned. One of them is the risk of neglecting important contextual factors due to the abstraction process. Furthermore, it can be challenging to find and interview experts. Additionally, while interviewing experts to develop potential use cases, it is important to determine which of the technologies have to be considered. In this study, MID technologies were considered in combination with DMT, resulting in use cases that came into being by the previously mentioned technology, and therefore, it could be not suitable for all iMMS.

RQ 2: Some critical factors regarding RQ 2 were found. The testing of iMMS requires a great deal of extra effort, and thus, a normal "design freeze" cannot be accomplished and consequently should not be included in the available EDP. To make matters worse, customers expect fast processing and high reliability from individualized products. In order to develop products quickly and reliably, product development methods, such as the design for manufacturing, are more important than ever. However, the application of such 
methods can be time-consuming. Therefore, it is worthwhile to define secured tolerance spaces that have already been tested before an order is placed. An example would be the available pre-knowledge about the maximum and minimum size a person can be in order to produce orthoses.

\section{Limitations}

This study provides an operational method and shows that it is sensible for iMMS to create a new EDP that also prescribes the necessary product development methods. In addition to its findings, the present study, however, has limitations, which must be taken into account when interpreting the results. Such limitations are:

- $\quad$ Based on the literature analysis, only MID technology and DMT were considered in the survey and during the creation of the use cases.

- The requirements for iMMS and the explanations of the requirements were defined and determined through 17 experts. With a larger population of experts, it is probable that additional requirements need to be identified.

- Even though the use case with the most effort has been conducted through a real case study, not all collected use cases could be conducted and, therefore, could not be validated.

- Detailed use cases were considered in this work, but use cases are often presented in a short and simple way. Thus, collecting detailed use cases remains a challenge.

\section{Conclusions and Further Work}

This work had the primary goal to systematically provide a solid groundwork based on use cases in order to establish a reference process for the development of iMMS. For this purpose, needs, critical points and existing approaches were identified, and a new approach was presented. Before that, the relevance of the work was shown, and definitions of the terms "mass customization" and "individualization" were collected. Subsequently, a new definition of the term iMMS was created. Due to the technology dependency of MMS, a technological framework for the manufacturing of iMMS was also established in Section 1 through previous work and a detailed literature review. These are MID technologies in combination with DMT. Based on these technologies, use cases for iMMS were created and collected through expert interviews. After creating a repertoire of use cases, a novel methodology to abstract use cases in product groups was developed that is based on qualitative content analysis. Then, the requirements for each use case were defined and evaluated with the experts. The abstraction of the use cases was an easement for defining requirements. Consequently, product groups were formed for the respective use cases, which have both the most important development activities gained through the qualitative content analysis and weighted requirements. Thus, the novel methodology allows a qualitative assignment of properties and characteristics to product groups with their weighted requirements. Finally, a real case study was conducted to analyze and confirm the manufacturability with MID technologies and DMT and to find suitable reference processes that can be later tailored to iMMS. Furthermore, the case study revealed weaknesses and gaps within the design process for iMMS. This case study also shows the integration of automated slides into soft tooling that is fabricated from the same material as the soft tooling and operated by the clamping forces of the injection-molding machine. This production process is also a novelty [29] and has not been investigated in the context of EDP. It is especially the necessary correction loops that have to be executed due to the individuality of the products, which is the main challenge in the development of iMMS. On top of that, digital technologies, such as additive manufacturing, must be used for the production of individualized products. Such technologies are new. Hence, very few empirical values are available. With the gained insights from this work, new research questions can be derived. One of these could be: Which product development methods can help reduce correction loops within the development and manufacturing of iMMS? This enables creating a novel EDP with the supported methods. Nonetheless, the defined 
requirements can expand and change as more use cases are collected. In the context of this work, it also became clear that valuable knowledge was gained through real case studies. A recommendation to identify further critical points of the design processes for iMMS is to implement and observe further real case studies.

Author Contributions: Conceptualization, F.C.; methodology, F.C.; validation, F.C. and K.-P.F. and A.Z.; formal analysis, F.C.; investigation, F.C.; resources, F.C.; data curation, F.C.; writing-original draft preparation, F.C.; writing—review and editing, F.C., K.-P.F. and A.Z.; visualization, F.C.; supervision, K.-P.F. and A.Z.; project administration, F.C.; funding acquisition, A.Z. All authors have read and agreed to the published version of the manuscript.

Funding: Baden-Württemberg's Ministry of Economic Affairs, Labour and Housing, Grant Number 213234 funded this research.

Institutional Review Board Statement: Not applicable.

Informed Consent Statement: Not applicable.

Conflicts of Interest: The authors declare no conflict of interest.

$\begin{array}{ll}\text { Abbreviations } \\ \text { CAD } & \text { Computer-aided design } \\ \text { CBR } & \text { Case-based reasoning } \\ \text { DMT } & \text { Digital manufacturing technologies } \\ \text { EDP } & \text { Engineering design process } \\ \text { iMMS } & \text { Individualized micro-mechatronic system(s) } \\ \text { LDS } & \text { Laser direct structuring } \\ \text { MID } & \text { Molded interconnect device(s) } \\ \text { MVP } & \text { Minimum valuable product } \\ \text { PUC } & \text { Paraphrased use case(s) } \\ \text { RQ } & \text { Research question } \\ \text { TEDP } & \text { Tailoring engineering design process } \\ \text { UGT } & \text { User goal technique } \\ \text { UML } & \text { Unified modeling language } \\ \text { VDI } & \text { German Association of Engineers }\end{array}$

\section{References}

1. Nacer, A.; Marhic, B.; Delahoche, L. Smart Home, Smart HEMS, Smart Heating: An Overview of the Latest Products and Trends. In Proceedings of the 2017 6th International Conference on Systems and Control (ICSC), Batna, Algeria, 7-9 May 2017; pp. 90-95.

2. Cronin, M.J. Smart Products, Smarter Services: Strategies for Embedded Control; Cambridge University Press: Cambridge, UK, 2010; ISBN 978-1-139-49029-0.

3. Dhungana, D.; Falkner, A.; Haselbock, A.; Taupe, R. Enabling Integrated Product and Factory Configuration in Smart Production Ecosystems. In Proceedings of the 43rd Euromicro Conference on Software Engineering and Advanced Applications (SEAA), Vienna, Austria, 30 August-1 September 2017; pp. 266-273.

4. Lanza, G.; Blank, T.; Haefner, B. Design for Testability for Micro-Mechatronic Systems. In Smart Product Engineering; Abramovici, M., Stark, R., Eds.; Springer: Berlin/Heidelberg, Germany, 2013; pp. 283-292.

5. A European Strategy for Key Enabling Technologies-A Bridge to Growth and Jobs. 2012. Available online: https:/ / eur-lex.europa. eu/LexUriServ/LexUriServ.do?uri=COM:2012:0341:FIN:EN:PDF (accessed on 19 July 2021).

6. A Stronger European Industry for Growth and Economic Recovery. 2012. Available online: https://eur-lex.europa.eu/ LexUriServ/LexUriServ.do?uri=COM:2012:0582:FIN:EN:PDF (accessed on 19 July 2021).

7. Huff, M. Process Variations in Microsystems Manufacturing; Springer Nature: Cham, Switzerland, 2020; ISBN 978-3-030-40560-1.

8. Michel, F.; Ehrfeld, W. Mechatronic Micro Devices. In Proceedings of the International Symposium on Micromechatronics and Human Science (Cat. No.99TH8478), Nagoya, Japan, 23-26 November 1999; pp. 27-34.

9. Wright, P.; Dornfeld, D.; Ota, N. Condition Monitoring in End-Milling Using Wireless Sensor Networks (WSNs). Trans. NAMRI/SME 2008, 36, 177-183. Available online: https:/ / escholarship.org/uc/item/7cp1p0ww (accessed on 21 July 2021).

10. Hodgins, D.; Bertsch, A.; Post, N.; Frischholz, M.; Volckaerts, B.; Spensley, J.; Wasikiewicz, J.M.; Higgins, H.; von Stetten, F.; Kenney, L. Healthy Aims: Developing New Medical Implants and Diagnostic Equipment. IEEE Pervasive Comput. 2008, 7, 14-21. [CrossRef] 
11. Liu, X.; Ogirala, A.; Berger, L.; Mickle, M. Design and Implementation of a Volume Conduction Based RFID System for Smart Implants. In Proceedings of the Annual International Conference of the IEEE Engineering in Medicine and Biology Society, Boston, MA, USA, 30 August-3 September 2011; pp. 2893-2896.

12. Franke, J. (Ed.) Three-Dimensional Molded Interconnect Devices (3D-MID): Materials, Manufacturing, Assembly and Applications for Injection Molded Circuit Carriers; Carl Hanser Verlag GmbH \& Co. KG: München, Germany, 2014; ISBN 978-1-56990-551-7.

13. Leneke, T.; Soeren, H.; Schmidt, B. A Multilayer Process for Fine-Pitch Assemblies on Molded Interconnect Devices (MIDs). In Proceedings of the 2nd Electronics System-Integration Technology Conference, Greenwich, UK, 1-4 September 2008; pp. 663-668.

14. Hoerber, J.; Glasschroeder, J.; Pfeffer, M.; Schilp, J.; Zaeh, M.; Franke, J. Approaches for Additive Manufacturing of 3D Electronic Applications. Procedia CIRP 2014, 17, 806-811. [CrossRef]

15. Ribeiro da Silva, E.H.D.; Angelis, J.; de Lima, E.P. In Pursuit of Digital Manufacturing. Procedia Manuf. 2019, 28, 63-69. [CrossRef]

16. Pfeifer, T. Quality Management: Strategies, Methods, Techniques, 3rd ed.; Completely Revised and Enlarged Edition; Hanser: München, Germany, 2002; ISBN 978-3-446-22402-5.

17. Gausemeier, J.; Gausemeier-Dumitrescu-Rammig-Schäfer-Trächtler (Eds.) Entwurf Mechatronischer Systeme: Grundlagen, Methoden und Werkzeuge, Adaption, Selbstoptimierung und Verlässlichkeit, Integration Mechanik und Elektronik, Miniaturisierung, Paderborner Workshop Entwurf Mechatronischer Systeme, 18 und April 2013, Heinz Nixdorf MuseumsForum; [unter dem Dach der Veranstaltung Wissenschaftsforum 2013-Intelligente Technische Systeme]; HNI-Verlagsschriftenreihe; Paderborn University, Heinz Nixdorf Institute: Paderborn, Germany, 2013; ISBN 978-3-942647-29-8.

18. Koren, Y.; Shpitalni, M.; Gu, P.; Hu, S.J. Product Design for Mass-Individualization. Procedia CIRP 2015, 36, 64-71. [CrossRef]

19. Schwesinger, N.; Dehne, C.; Adler, F. Lehrbuch Mikrosystemtechnik: Anwendungen, Grundlagen, Materialien und Herstellung von Mikrosystemen; Oldenbourg: München, Germany, 2009; ISBN 978-3-486-57929-1.

20. Shi, F.; Ramesh, P.; Mukherjee, S. Dynamic Analysis of Micro-Electro-Mechanical Systems. Int. J. Numer. Methods Eng. 1996, 39, 4119-4139. [CrossRef]

21. Ishihara, H.; Arai, F.; Fukuda, T. Micro Mechatronics and Micro Actuators. IEEE/ASME Trans. Mechatron. 1996, 1, 68-79. [CrossRef]

22. Dario, P.; Carrozza, M.C.; Allotta, B.; Guglielmelli, E. Micromechatronics in Medicine. IEEE/ASME Trans. Mechatron. 1996, 1, 137-148. [CrossRef]

23. Reynaerts, D.; Peirs, J.; van Brussel, H. A Mechatronic Approach to Microsystem Design. IEEE/ASME Trans. Mechatron. 1998, 3 , 24-33. [CrossRef]

24. Reinhardt, A.; Franke, J.; Goth, C. Reliability of Micromechatronic Systems with Chip on Molded Interconnected Devices and Flexible Substrates. In Proceedings of the 12th Electronics Packaging Technology Conference, Singapore, 8-10 December 2010; pp. 79-83.

25. Islam, A.; Hansen, H.N.; Tang, P.T.; Sun, J. Process Chains for the Manufacturing of Molded Interconnect Devices. Int. J. Adv. Manuf. Technol. 2009, 42, 831-841. [CrossRef]

26. Heininger, N.; John, W.; Boßler, H.-J. Manufacturing of Molded Interconnect Devices from Prototyping to Mass Production with Laser Direct Structuring. In Proceedings of the 2004 9th MID-Conference. Available online: http:/ / citeseerx.ist.psu.edu/ viewdoc/download?doi=10.1.1.628.6206\&rep=rep1\&type=pdf (accessed on 19 July 2021).

27. Orlob, C.; Kornek, D.; Preihs, S.; Rolfes, I. Characterization of Electromagnetic Properties of Molded Interconnect Device Materials. In Proceedings of the German Microwave Conference, Munich, Germany, 16-18 March 2009; pp. 1-4.

28. Laur, V.; Mattei, J.-L.; Vérissimo, G.; Queffelec, P.; Lebourgeois, R.; Ganne, J.-P. Application of Molded Interconnect Device Technology to the Realization of a Self-Biased Circulator. J. Magn. Magn. Mater. 2016, 404, 126-132. [CrossRef]

29. Vieten, T.; Stahl, D.; Schilling, P.; Civelek, F.; Zimmermann, A. Feasibility Study of Soft Tooling Inserts for Injection Molding with Integrated Automated Slides. Micromachines 2021, 12, 730. [CrossRef]

30. Hales, C.; Gooch, S. Managing Engineering Design; Springer: London, UK, 2004; ISBN 978-1-4471-1053-8.

31. Frankenberger, E.; Badke-Schaub, P. Integration of Group, Individual and External Influences in the Design Process. In Designers; Frankenberger, E., Birkhofer, H., Badke-Schaub, P., Eds.; Springer: London, UK, 1998; pp. 149-164. ISBN 978-1-4471-1270-9.

32. Maffin, D.; Thwaites, A.; Alderman, N.; Braiden, P.; Hills, B. Managing the Product Development Process: Combining Best Practice with Company and Project Contexts. Technol. Anal. Strateg. Manag. 1997, 9, 53-76. [CrossRef]

33. Brooks, F.P. The Mythical Man-Month: Essays on Software Engineering; Anniversary, Ed.; Addison-Wesley Pub. Co.: Reading, MA, USA, 1995; ISBN 978-0-201-83595-3.

34. Fitzgerald, B.; Russo, N.L.; O’Kane, T. Software Development Method Tailoring at Motorola. Commun. ACM 2003, 46, 64-70. [CrossRef]

35. Brinkkemper, S. Method Engineering: Engineering of Information Systems Development Methods and Tools. Inf. Softw. Technol. 1996, 38, 275-280. [CrossRef]

36. ter Hofstede, A.H.M.; Verhoef, T.F. On the Feasibility of Situational Method Engineering. Inf. Syst. 1997, 22, 401-422. [CrossRef]

37. Cockburn, A. Selecting a Project's Methodology. IEEE Softw. 2000, 17, 64-71. [CrossRef]

38. Xu, P.; Ramesh, B. Using Process Tailoring to Manage Software Development Challenges. IT Prof. 2008, 10, 39-45. [CrossRef]

39. Kalus, G.; Kuhrmann, M. Criteria for Software Process Tailoring: A Systematic Review. In Proceedings of the 2013 International Conference on Software and System Process, San Francisco, CA, USA, 18-19 May 2013; ACM Press: New York, NY, USA, 2013 ; p. 171. 
40. Hollauer, C.; Lindemann, U. Design Process Tailoring: A Review and Perspective on the Literature. In Research into Design for Communities, Volume 1; Chakrabarti, A., Chakrabarti, D., Eds.; Smart Innovation, Systems and Technologies; Springer: Singapore, 2017; Volume 65, pp. 609-618. ISBN 978-981-10-3517-3.

41. Park, S.-H.; Bae, D.-H. Tailoring a Large-sized Software Process Using Process Slicing and Case-based Reasoning Technique. IET Softw. 2013, 7, 47-55. [CrossRef]

42. Watson, I.; Marir, F. Case-Based Reasoning: A Review. Knowl. Eng. Rev. 1994, 9, 327-354. [CrossRef]

43. Du Preez, N.; Lutters, D.; Nieberding, H. Tailoring the Development Process According to the Context of the Project. CIRP J. Manuf. Sci. Technol. 2009, 1, 191-198. [CrossRef]

44. Watty, R.; Binz, H. Methodology for the Development of Micro-Electro-Mechanical-Systems. In Proceedings of the ICED 2007, The 16th International Conference on Engineering Design, Paris, France, 28-31 July 2007; pp. 197-198.

45. Hellenbrand, D.; Lindemann, U. A Framework for Integrated Process Modeling and Planning of Mechatronic Products. In Proceedings of the 18th International Conference on Engineering Design (ICED 11), Impacting Society through Engineering Design, Vol. 1: Design Processes, Lyngby/Copenhagen, Denmark, 15-19 August 2011; Design Society: Castle Cary, UK, 2013; pp. 521-530.

46. DRM: A Design Reseach Methodology. In DRM, a Design Research Methodology; Springer: London, UK, 2009; pp. 13-42, ISBN 978-1-84882-586-4.

47. Satzinger, J.W.; Jackson, R.B.; Burd, S.D. Systems Analysis and Design: In a Changing World, 7th ed.; Cengage Learning: Boston, MA, USA, 2016; ISBN 978-1-305-11720-4.

48. Glinz, M. Problems and Deficiencies of UML as a Requirements Specification Language. In Proceedings of the 10th International Workshop on Software Specification and Design, IWSSD-10 2000, San Diego, CA, USA, 5-7 November 2000; pp. 11-22.

49. Mayring, P. Qualitative Inhaltsanalyse: Grundlagen und Techniken; 12., überarbeitete Auflage; Beltz Verlag: Basel, Switzerland, 2015; ISBN 978-3-407-25730-7.

50. Mayring, P. Qualitative Content Analysis: Theoretical Background and Procedures. In Approaches to Qualitative Research in Mathematics Education; Bikner-Ahsbahs, A., Knipping, C., Presmeg, N., Eds.; Advances in Mathematics Education; Springer Netherlands: Dordrecht, The Netherlands, 2015; pp. 365-380. ISBN 978-94-017-9180-9.

51. Ungerer, F.; Schmid, H.-J. (Eds.) An Introduction to Cognitive Linguistics, 2nd ed.; Longman: New York, NY, USA, 2006; ISBN 978-0582-78496-3.

52. Jacobson, I. Object-Oriented Software Engineering: A Use Case Driven Approach; ACM Press/Addison-Wesley Professional: Wokingham, UK; Reading, MA, USA, 1992; ISBN 978-0-201-54435-0.

53. Jacobson, I.; Spence, I.; Kerr, B. Use-Case 2. Commun. ACM 2016, 59, 61-69. [CrossRef]

54. Jarzabek, S.; Ling, T.W. Model-Based Support for Business Re-Engineering. Inf. Softw. Technol. 1996, 38, 355-374. [CrossRef]

55. Lindemann, U.; Venkataraman, S.; Kim, Y.S.; Cantamessa, M.; Yannou, B. (Eds.) Volume 3: Design Organisation and Management Design. In Proceedings of the 19th International Conference on Engineering Design, Seoul, Korea, 19-22 August 2013; Design Society: Castle Cary, UK, 2013; ISBN 978-1-904670-46-9.

56. Fernandes, J.; Henriques, E.; Silva, A.; Moss, M.A. Requirements Change in Complex Technical Systems: An Empirical Study of Root Causes. Res. Eng. Des. 2015, 26, 37-55. [CrossRef]

57. Hamraz, B.; Caldwell, N.H.M.; Wynn, D.C.; Clarkson, P.J. Requirements-Based Development of an Improved Engineering Change Management Method. J. Eng. Des. 2013, 24, 765-793. [CrossRef]

58. Kaiser, F.-J. (Ed.) Die Fallstudie: Theorie und Praxis der Fallstudiendidaktik; Forschen und Lernen; Klinkhardt: Bad Heilbrunn, Germany, 1983; ISBN 978-3-7815-0506-3.

59. Yin, R.K. Case Study Research and Applications: Design and Methods, 6th ed.; SAGE: Los Angeles, CA, USA, 2018; ISBN 978-1-5063-3616-9.

60. Working Group 3D Elektronic/Arbeitskreis 3D-Elektronik. Available online: https://www.fed.de/verband/arbeitskreise/ arbeitskreis-3d-elektronik/?L=0 (accessed on 30 May 2021).

61. VDI. Design Handbook 2206. In Design Methodology for Mechatronic Systems; VDI Publishing Group: Düsseldorf, Germany, 2004. 